\title{
Bone resorption in incompletely impacted mandibular third molars and acute pericoronitis
}

\author{
Minoru Yamaoka \\ Yusuke Ono \\ Masahiro Takahashi \\ Ryosuke Doto \\ Kouichi Yasuda \\ Takashi Uematsu \\ Kiyofumi Furusawa
}

Matsumoto Dental University School of Dentistry, Shiojiri, Nagano, Japan
Correspondence: Minoru Yamaoka Matsumoto Dental University School of Dentistry, Shiojiri, Nagano 399-078I, Japan

Fax +8I 263 5I 2076

Emailyamaoka@po.mdu.ac.jp

\begin{abstract}
Acute pericoronitis (AP) arises frequently in incompletely impacted mandibular third molars, but it remains unknown whether bone resorption in aging is associated with acute inflammation of the third molar. We conducted an experiment to compare the ratio of bone resorption to root length in the distal surface of the second molar (A), the proximal surface (B), and distal surface (C) in mesio-angular, incompletely impacted third molars in 27 young and 58 older adults with AP and 77 young and 79 older adults without a history of AP. Bone resorption in $\mathrm{A}, \mathrm{B}$, and $\mathrm{C}$ in older adults with AP demonstrated a significantly higher ratio when compared to those without AP, whereas there was no difference between those with and without AP in young adults except for B in women. However, there were no differences between bone resorption in $\mathrm{B}$ with $\mathrm{AP}$ in young and older women, and between bone resorption in $\mathrm{C}$ with $\mathrm{AP}$ in young and older adults. These indicate that AP and bone resorption are associated with incompletely impacted mandibular third molars in older adults.
\end{abstract}

Keywords: bone resorption, pericoronitis, mandible, acute inflammation, elderly

\section{Introduction}

Acute pericoronitis (AP) is frequently seen in incompletely impacted third molars, and leads to a marked increase in bone resorption, although considerable radiologic changes may occur without notable symptoms, involving inclination of the tooth and the state of impaction after the usual age of eruption. ${ }^{1}$ Moreover, the alveolar bone loss on the distal side of the second molar has been well described in horizontal impacted third molar, regardless of the presence of AP..$^{2-7}$ On the other hand, a correlation between the inflammatory infiltrate and histological alveolar bone loss has been observed, ${ }^{8}$ and endothelial-derived cytokines, ${ }^{9} \mathrm{~T}$ cells,,${ }^{10-13}$ mast cells, ${ }^{14}$ and interleukin-1 (IL-1) ${ }^{15,16}$ may be involved in bone resorption. Hou and colleagues ${ }^{17}$ noted that intact Toll-like receptor (TLR) function mediates increased proinflammatory responses and bone destruction in response to mixed anaerobic infections, while there is a reduction of bone destruction in TLR4- ${ }^{17}$ and TLR2-deficient mice. ${ }^{18}$ Moreover, a transient inhibition of bone formation during acute inflammation has also been shown. ${ }^{19}$ However, it remains to be determined whether the level of bone resorption is associated with the emergence of AP. We postulated that AP in young individuals differed from that in the elderly possibly due to chronic inflammation in aging leading to bone resorption. The objective of the present study was to clarify the relationship between the degree of radiolucency and acute inflammation with aging in mesio-angular incomplete impaction.

\section{Methods}

Radiological examination of the following was performed: 12 teeth of 12 young men (mean age $\pm \mathrm{SD}: 19.8 \pm 1.5$ years; range: $18-22$ years), 32 teeth of 32 older men (mean age \pm SD: $49.5 \pm 6.1$ years; range: $41-67$ years), 15 teeth of 15 young women (mean age \pm SD: $20.0 \pm 1.5$ years; range: $18-22$ years), and 
26 teeth of 26 older women (mean age \pm SD: $50.5 \pm 8.6$ years; range: $41-82$ years). On initial examination, these patients had acute inflammation with spontaneous pain, redness, and swelling of the gingiva around incompletely impacted mesio-angular mandibular third molars. Some patients also had functional disorders of mastication, trismus and/or difficulty in swallowing. Patients with AP were administered a dose of antibiotics and antiinflammatory drugs. Thirty-eight teeth of 30 young men (mean age $\pm \mathrm{SD}, 20.2 \pm 1.3$ years; range: $18-22$ years), 51 teeth of 49 older men (mean age $\pm \mathrm{SD}, 47.4 \pm 6.0$ years; range: $41-68$ years), 55 teeth of 47 young women (mean age $\pm \mathrm{SD}, 20.5 \pm 1.3$ years; range: $18-22$ years), and 33 teeth of 30 older women (mean age $\pm \mathrm{SD}, 47.7 \pm 6.2$ years; range: 41-69 years) showed no features of inflammation. Moreover, the patients did not have any history of acute inflammation of the third molars. These patients were referred to the Department of Oral and Maxillofacial Surgery, Matsumoto Dental University Hospital, for diagnosis and treatment between April 1985 and August 2005. All patients with AP on initial examination were selected, and those without AP were classified based on the absence of acute inflammation on initial examination, as well as their response to a questionnaire regarding the absence of acute inflammation. All the participants were Japanese, and all of them were covered by the Japanese health insurance system. Patients with the following conditions at the initial examination were excluded from the study: patients with apical radiolucency of the second or third molar, root fragment of the second or third molar, an unreadable crestal status because of teeth crowding between the second and third molars, restoration ending below the cemento-enamel junction of the second or third molar, cyst in the second and/or third molars, loss of the second molar, complete impaction of the third molar, a vertical third molar, distal inclination of the third molar, third molars with root curvatures angled more than $90^{\circ}$ to the long axis of the tooth at the point close to the apex in the cervico-apical direction, and patients with immunosuppressive conditions, including AIDS.

Radiographs were obtained with an X-ray machine (Morita Corp., Tokyo or Asahi Roentgen Co., Kyoto, Japan) and UltraSpeed Dental Film (Eastman Kodak, Rochester, NY, USA) at $70 \mathrm{kVp}$ and $20 \mathrm{~mA}$ in $0.32 \mathrm{~s}$ or Insight dental film (Eastman Kodak) at $70 \mathrm{kVp}$ and $7 \mathrm{~mA}$ in $0.16 \mathrm{~s}$ using the parallel technique. Reference points for measurements are shown in Figure 1. The bone crest of the distal aspect of the second molar, that of the proximal aspect of the third molar, and that of the distal aspect

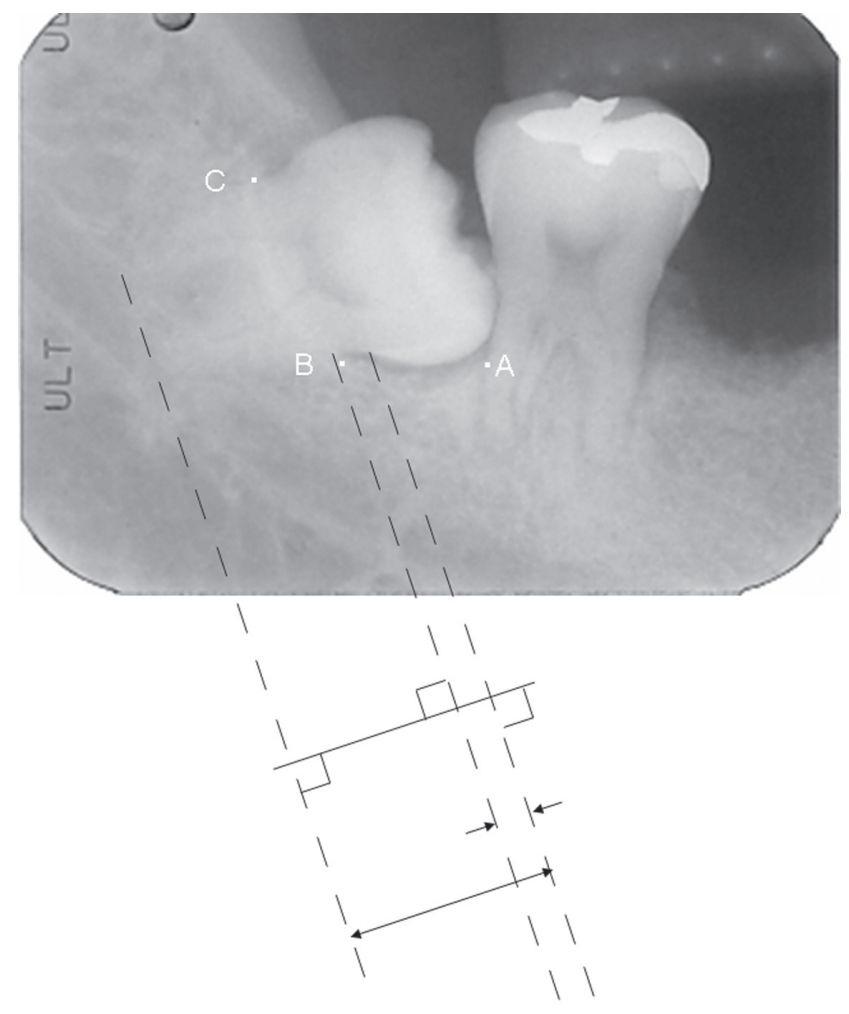

Figure I Schematic drawing presenting the method of measurement of the radiographic cervico-apical lengths and the distances between the cemento-enamel junction and crest of the bone on the long axis of the tooth. The distance was measured on both the proximal and distal aspects of the third molar.

of the third molar are shown as points A, B, and C, respectively. The bone crest is shown by the point where the periodontal space becomes parallel to the root surface. Resorption of the bone crest was assessed by visual observation using a millimeter ruler and $2 \times$ magnification. Measurements were rounded to the nearest $0.5 \mathrm{~mm}$. The radiographs were measured by the linear distance from the cemento-enamel junction to the alveolar crest and the cemento-enamel junction to the apex of both proximal and distal roots, respectively, and evaluated for the ratio of bone crest resorption against the root length from the cemento-enamel junction to the apex in the proximal and distal aspects of the third molar and the distal aspect of the second molar. Measurement of radiograms were performed twice by the same oral surgeon; the second time being performed after a period of few months without seeing the primary data. The mean values of both the measurements were calculated. Teeth with bone resorption which could not be measured, and thereby the length, at any point on either measurement were excluded from the study.

\section{Statistical analysis}

Mean values \pm SD of the age and mean ratios of the bone crest in the distal aspect in the second molar and those in the proximal and distal aspects in the third molar were calculated 
and analyzed statistically using Student $t$-test among patient groups with and without AP.

\section{Results}

Bone resorption in the distal aspect of the second molar (A), proximal (B) and distal (C) aspects of the third molar in young men with AP was not different from those without AP. Bone resorption in young adult women with AP was also not different from those without AP except in the proximal aspect of the third molar (B). Bone resorption in older adult men and women with AP was significantly higher than those without $\mathrm{AP}$ at the points of $\mathrm{A}, \mathrm{B}$, and $\mathrm{C}$, respectively $(\mathrm{p}<0.0001$, $\mathrm{p}<0.001$, and $\mathrm{p}<0.01$ in men, and $\mathrm{p}<0.0001, \mathrm{p}<0.001$, and $\mathrm{p}<0.001$ in women) (Table 1) (Figures 2-5).

The level of bone resorption in the distal aspect of the second molars was $68 \%$ in older men, and $67.7 \%$ in older women, and significantly higher than those in the proximal surface $(25.3 \%, \mathrm{p}<0.0001$ in men, and $16.4 \%, \mathrm{p}<0.0001$ in women, and distal $(20 \%, \mathrm{p}<0.0001$ in men, and $17.1 \%$, $\mathrm{p}<0.0001$ in women) aspect with AP. The findings in older adults were similar to those in young adults with AP.

In older adults without AP, bone resorption between the distal aspect of the second molar (42.2\% in men, and 38.1\% in women) and the proximal aspect of the third molar ( $9 \%$ in men, and $2.8 \%$ in women), showed a significant difference $(\mathrm{p}<0.0001$ in both). The difference between bone resorption in the distal aspect of the second molar and the distal aspect of the third molar $(6.3 \%$ in men, and $1.3 \%$ in women) was also significant ( $p<0.0001$ in both). No apparent difference was noted between bone resorption in the proximal and distal aspects of the third molar in both men and women. These findings were the same in young adults without AP.

In adults with AP, bone resorption at the distal aspect of the second molar showed a significant difference $(\mathrm{p}<0.0001$ in men and women) between young and older adults, as well as at the proximal aspect of the third molar $(\mathrm{p}<0.05)$. However, no apparent difference was noted between bone resorption at the proximal aspect of the third molar in young and older women. There were no differences in bone resorption at the distal aspect of the third molar between young and older adults (in both of men and women).

In adults without AP, bone resorption at the distal aspect of the second molar between young and older adults showed significant difference ( $p<0.01$ in men and women). There was no difference in bone resorption at the proximal aspect of the third molar between young and older adults. No difference was seen in bone resorption at the distal aspect of the third molar between young and older adults.

Table I Bone resorption in young adults and older adults with or without AP

\begin{tabular}{|c|c|c|c|c|c|c|}
\hline Age (y) & $18-22$ & & & $4 I \leq$ & & \\
\hline AP & With & Without & $\mathbf{P}$ & With & Without & $\mathbf{P}$ \\
\hline \multicolumn{7}{|c|}{$\begin{array}{l}\text { Mean } \pm \text { SD of years of age } \\
\text { ( } n: \text { number of subjects) }\end{array}$} \\
\hline Men & $19.833 \pm 1.467(12)$ & $20.167 \pm 1.289(30)$ & ns & $49.469 \pm 6.069(32)$ & $47.449 \pm 6.000(49)$ & ns \\
\hline Women & $20.000 \pm 1.464(15)$ & $20.489 \pm 1.266(47)$ & ns & $50.462 \pm 8.613(26)$ & $47.700 \pm 6.249(30)$ & ns \\
\hline \multicolumn{7}{|c|}{ Number of teeth } \\
\hline Men & 12 & 38 & & 32 & 51 & \\
\hline Women & 15 & 55 & & 26 & 33 & \\
\hline \multicolumn{7}{|c|}{$\begin{array}{l}\text { Bone resorption at the distal } \\
\text { aspect of the second molar (A) }\end{array}$} \\
\hline Men & $0.227 \pm 0.086^{\mathrm{a}}$ & $0.290 \pm 0.167^{\mathrm{a}, \mathrm{b}}$ & ns & $0.680 \pm 0.249^{a}$ & $0.422 \pm 0.209^{\mathrm{a}, \mathrm{b}}$ & $\mathrm{P}<0.000 \mathrm{I}$ \\
\hline Women & $0.187 \pm 0.115^{\mathrm{a}, \mathrm{b}, \mathrm{c}}$ & $0.26 \mathrm{I} \pm 0.16 \mathrm{I}^{\mathrm{a}, \mathrm{b}}$ & ns & $0.677 \pm 0.186^{\mathrm{a}}$ & $0.381 \pm 0.166^{\mathrm{a}, \mathrm{b}}$ & $\mathrm{P}<0.000 \mathrm{I}$ \\
\hline \multicolumn{7}{|c|}{$\begin{array}{l}\text { Bone resorption at the proximal } \\
\text { aspect of the third molar (B) }\end{array}$} \\
\hline Men & $0.063 \pm 0.074^{\mathrm{a}, \mathrm{c}}$ & $0.056 \pm 0.056^{b}$ & ns & $0253 \pm 0256^{\mathrm{a}, \mathrm{c}}$ & $0090 \pm 0144^{a}$ & $\mathrm{P}<0.00 \mathrm{I}$ \\
\hline Women & $0.086 \pm 0.101^{c}$ & $0.041 \pm 0.056^{\mathrm{a}}$ & $\mathrm{p}<0.05$ & $0.164 \pm 0.206^{\mathrm{a}}$ & $0.028 \pm 0.059^{a}$ & $\mathrm{P}<0.00 \mathrm{I}$ \\
\hline \multicolumn{7}{|c|}{$\begin{array}{l}\text { Bone resorption at the distal } \\
\text { aspect of the third molar (C) }\end{array}$} \\
\hline Men & $0.066 \pm 0.06 \mathrm{~S}^{\mathrm{a}}$ & $0.057 \pm 0.069^{a}$ & ns & $0.200 \pm 0.28 \mathrm{I}^{\mathrm{a}}$ & $0.063 \pm 0.10 \mathrm{I}^{\mathrm{a}}$ & $\mathrm{P}<0.0 \mathrm{I}$ \\
\hline Women & $0.068 \pm 0.060^{b}$ & $0.077 \pm 0.096^{a}$ & ns & $0.171 \pm 0.249^{a}$ & $0.013 \pm 0.039^{a}$ & $\mathrm{P}<0.001$ \\
\hline
\end{tabular}

Notes: ${ }^{\mathrm{a}} \mathrm{p}<0.0001,{ }^{\mathrm{b}} \mathrm{p}<0.01,{ }^{\mathrm{c}} \mathrm{p}<0.05$.

Abbreviations: ns, net significant; SD, standard deviation. 


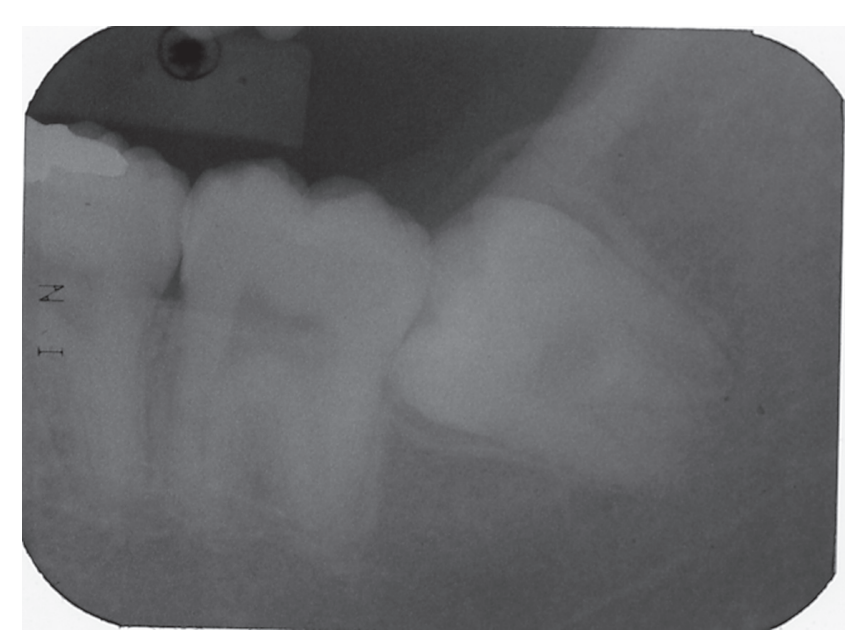

Figure 2 Left mandibular third molar of an 18-year-old man without acute pericoronitis.

Moreover, SD in these data in older adults was larger than that in young individuals.

\section{Discussion}

The present study included patients who had acute inflammation in the mesio-angular, incompletely impacted, mandibular third molars, and those without a history of acute inflammation, as assessed by a questionnaire. A remarkable increase in the mean depth of bone resorption was seen in incompletely impacted third molars at the points of A, B, and $\mathrm{C}$ in older adults with AP, unlike in young adults, except in the proximal aspect of the third molar in young women. Older adults without AP showed significant bone resorption at point A compared to young adults $(\mathrm{p}<0.01)$, and there were no differences at $\mathrm{B}$ and $\mathrm{C}$. There seems to be not much difference compared to participants with AP. Thus, increased radiolucency in individuals of middle or advanced age renders bone

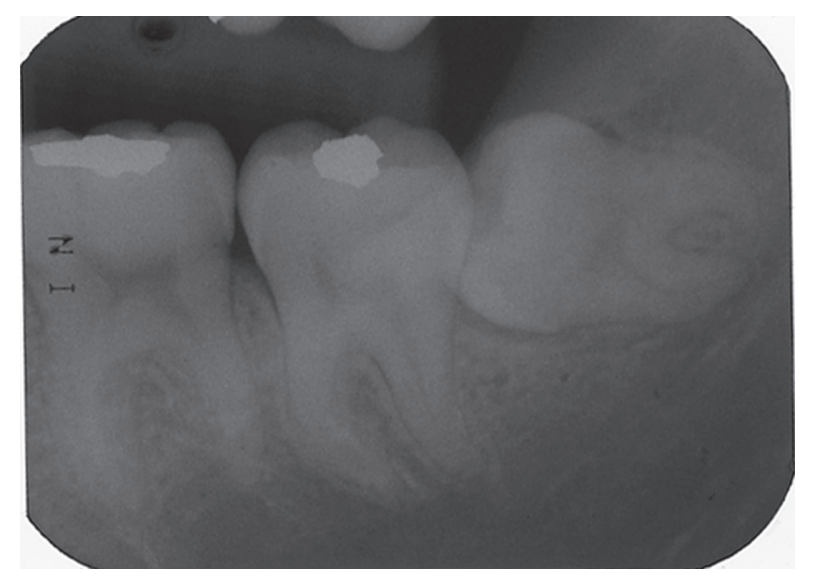

Figure 3 Left mandibular third molar of a 19-year-old woman with acute pericoronitis.

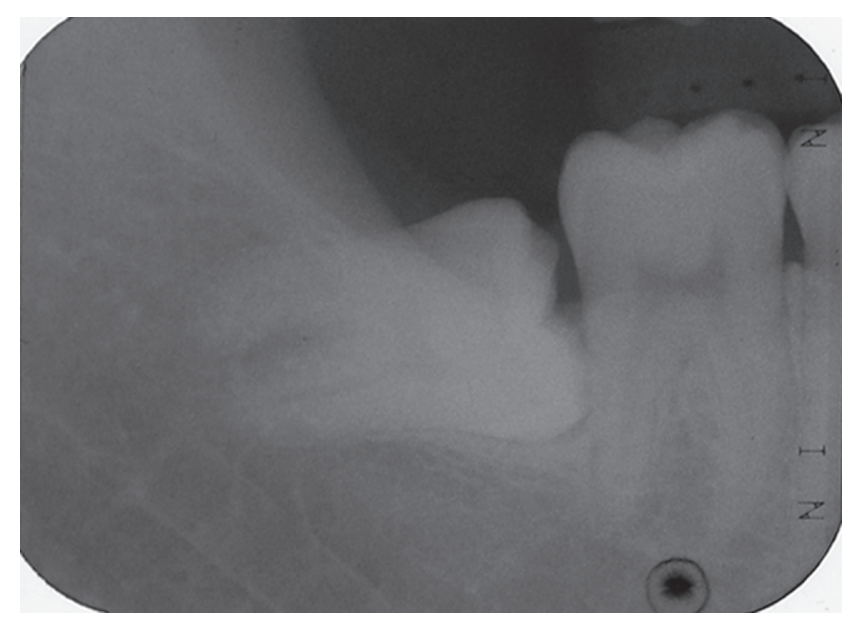

Figure 4 Right mandibular third molar of a 41 -year-old man with acute pericoronitis.

sensitive to infection. This is supported by the finding that $\mathrm{T}$ cells may regulate bone loss during chronic inflammation, as noted by Rifas and colleagues. ${ }^{13}$ Bone resorption, which seems to be an etiological factor leading to the emergence of current AP, is likely to be accelerated as a pronounced effect with aging, whereas there is a threshold age of 25 years for improvement of the alveolar bone level, as shown by Kugelberg ${ }^{6}$ and Blakey and colleagues. ${ }^{2}$ Rapid progression of infection can be followed by absence of resistance due to loss of periodontal membrane around the crown of incompletely impacted third molars. These indicate that bone defects could allow pathogenic infection through the bone surfaces and/or reduce periodontal tissue defense. On the contrary, steadystate bone may maintain an anti-inflammatory state in older adults without AP, and resistance to AP could be demonstrated by the level of bone resorption. Thus, bone resorption might be a factor for the prediction of risk of the emergence of AP in older adults, if pre-existing bone resorption due to chronic inflammation could effect a rise of AP. Indeed, age-related decrease of bone of mandible ${ }^{20,21}$ has been well-known as a physiological consequence of aging, and Cao and colleagues ${ }^{22}$ have shown that aging significantly increases stromal/osteoblastic cell-induced osteoclastogenesis, promotes expansion of the osteoclast precursor pool and alters the relationship between osteoblasts and osteoclasts in cancellous bone. However, the value of these findings for prediction of risk of acute inflammation is limited. Bone resorption could be a response to AP, since AP contributes to not only the decrease in bone formation but also aggressive bone resorption. Il-123,24 and tumor necrosis factor, ${ }^{23}$ cytosolic phospholipase $\mathrm{A}_{2}-\alpha,{ }^{25}$ prostaglandin $\mathrm{E}_{2}\left(\mathrm{PGE}_{2}\right),{ }^{26}$ cytokine signaling- 1 and $-3,{ }^{27} \mathrm{PGE}$ synthases, ${ }^{28}$ and $\mathrm{Th}^{29}$ have been viewed to promote severe 


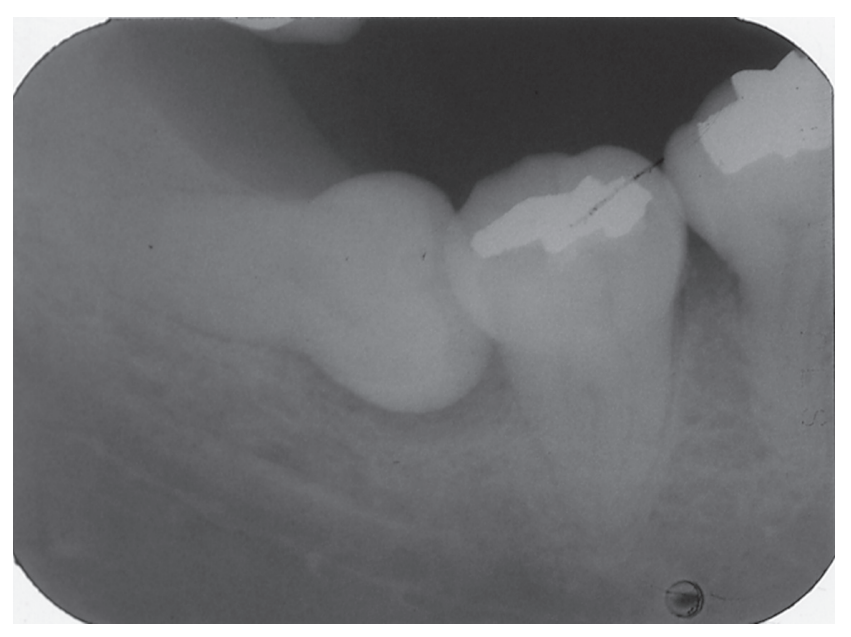

Figure 5 Right mandibular third molar of a 49 -year-old woman with acute pericoronitis.

bone resorption. Further studies are necessary to assess the effect of AP on bone resorption.

The significant increase of bone resorption at all of the distal aspects of the second molar (A), and the proximal (B) and the distal (C) aspects of the third molar in older adults with AP compared with older adults without AP suggest a threshold for an increase of AP in A, B, and C; with A having the most important association with an increase of AP. No differences were seen at B between young and older women with $\mathrm{AP}$, and at $\mathrm{C}$ between young and older adults with AP. An increased bone resorption at A in older adults without AP was seen compared to young adults without AP ( $p<0.01$ in both men and women), which seems to show no significant difference between them, whereas, there were no differences regarding $\mathrm{B}$ in older and young adults without $A P$, and regarding point $C$ in older and young adults without AP. These suggest that the effects of aging could be appended to a threshold for a rise of AP in A in the older adults. Vertical bone resorption seen in A could be characterized by aging as shown in alveolar bone resorption of periodontitis, whereas ventro-dorsal directional bone resorption seen in B and C could not be influenced by aging. Naturally, bone resorption in the mandible could not develop along the tooth axis but vertically with aging. Thus, the elderly might be expected to develop AP and bone resorption when compared to young adults. Various factors might define a threshold for the development of AP as a consequence of aging, since the elderly have latent instability of physiological capacity, and decreased protection from pathogens due to low immunological and neutrophil functions.

It was also found that bone resorption at the proximal and distal aspects of the third molar with AP in the older adults showed a larger SD than bone resorption in young adults and bone resorption without AP, indicating a substantial proportion of the marked inter-individual variation in the mean depth of bone resorption in older adults with AP. This finding indicates that responses to chronic pericoronitis could be viewed as an inter-individual variability in immunoinflammatory mechanism, biological aging as well as the individual's medical history. This variation seems to be similar to the perceptions of pain in the elderly. Wide individual variation including other clinical correlations and genetic associations should be studied regarding the development of AP in the elderly, incorporating a longitudinal design to determine the prerequisites for AP.

Furthermore, the reasons for the significant increase of bone resorption at the proximal aspect (B) in young women with $\mathrm{AP}$ than without $\mathrm{AP}$ was unclear, although estrogen may exert its bone-sparing effects on periodontal tissues by altering the expression of inflammatory cytokines in human periodontal ligament cells. ${ }^{30}$ This finding may be the likely result of a temporal phenomenon seen in the young against stimuli of acute inflammation, or due to a statistical problem of a small sample.

In conclusion, bone resorption was not related to acute pericoronitis in young individuals but related in older adults. Incompletely impacted third molars with significant bone resorption should point to acute inflammation in the elderly, since AP might be associated with bone resorption.

\section{Acknowledgments}

This work was performed as a part consignment for the Creation and Support Program for Start-ups from Universities of the Japan Science and Technology Agency. We would like to thank Ms Hitomi Koike and Ms Shiho Kobayashi for their secretarial assistances.

\section{Disclosures}

The authors report no conflicts of interest in this work.

\section{References}

1. Venta I, Turtola L, Ylipaavalniemi P. Radiographic follow-up of impacted third molars from 20 to 32 years. Int J Oral Maxillofac Surg. 2001;30(1):54-57.

2. Blakey GH, Marciani RD, Haug RH. et al. Periodontal pathology associated with asymptomatic third molars. J Oral Maxillofac Surg. 2002;60(11):1227-1233.

3. Kan KW, Liu JK, Lo EC, Corbet FF, Leung WK. Residual periodontal defects distal to the mandibular second molar 6-36 months after impacted third molar extraction. J Clin Periodontol. 2002;29(11):1004-1011.

4. Krausz AA, Machtei EE, Peled M. Effects of lower third molar extraction on attachment level and alveolar bone height of the adjacent second molar. Int J Oral Maxillofac Surg. 2005;34(7):756-760. 
5. Kugelberg CF, Ahlstrom U, Ericson S, Hugoson A. Periodontal healing after impacted lower third molar surgery: A retrospective study. Int J Oral Surg. 1985;14(1):29-40.

6. Kugelberg CF. Periodontal healing two and four years after impacted lower third molar surgery: A comparative retrospective study. Int $J$ Oral Maxillofac Surg. 1990;19(6):341-345.

7. Kugelberg CF, Ahlstrom U, Ericson S, Hugoson A, Thilander H. The influence of anatomical, pathophysiological and other factors on periodontal healing after impacted lower third molar surgery: A multiple regression analysis. J Clin Periodontol. 1991;18(1):37-43.

8. Rowe DJ, Bradley LS. Quantitative analyses of osteoclasts, bone loss and inflammation in human periodontal disease. J Periodontal Res. 1981;16(1):13-19.

9. Krishnaswamy G, Kelley J, Yerra L, Smith JK, Chi DS. Human endothelium as a source of multifunctional cytokines: molecular regulation and possible role in human disease. J Interferon Cytokine Res. 1999;19(2):91-104.

10. Baker PJ, Howe L, Garneau J, Roopenian DC. T cell knockout mice have diminished alveolar bone loss after oral infection with Porphyromonas gingivalis. FEMS Immunol Med Microbiol. 2002;34(1):45-50.

11. Gao Y, Quan WP, Dark K, et al. Estrogen prevents bone loss through transforming growth factor beta signaling in T cells. Proc Natl Acad Sci U S A. 2004;101(47):16618-16623.

12. Hara Y, Ukai T, Yoshimura A, Shiku H, Kato I. Histopathological study of the role of CD4- and CD8-positive T cells on bone resorption induced by Escherichia coli endotoxin. Calcif Tissue Int. 1998;63(1):63-66.

13. Rifas L, Arackal S, Weitzmann MN. Inflammatory $\mathrm{T}$ cells rapidly induce differentiation of human bone marrow stromal cells into mature osteoblasts. J Cell Biochem. 2003;88(4):650-659.

14. Fouilloux I, Duplan MB, Baroukh B, Cherruau M, Saffar JL, Lesclous P. Mast cell activation and degranulation occur early during induction of periosteal bone resorption. Bone. 2006;38(1):59-66.

15. Ishihara $Y$, Nishihara $T$, Kuroyanagi $T$, et al. Gingival crevicular interleukin-1 and interleukin-1 receptor antagonist levels in periodontally healthy and diseased sites. J Periodontal Res. 1997;32(6): 524-529.

16. Sjogren U, Mukohyama H, Roth C, Sundqvist G, Lerner UH. Bone-resorbing activity from cholesterol-exposed macrophages due to enhanced expression of interleukin-1 alpha. J Dent Res. 2002;81(1):11-16.

17. Hou L, Sasaki H, Stashenko P. Toll-like receptor 4-deficient mice have reduced bone destruction following mixed anaerobic infection. Infect Immun. 2000;68(8):4681-4687.
18. Burns E, Bachrach G, Shapira L, Nussbaum G. Cutting Edge: TLR2 is required for the innate response to Porphyromonas gingivalis: activation leads to bacterial persistence and TLR2 deficiency attenuates induced alveolar bone resorption. J Immunol. 2006;177(12):8296-8300.

19. Pfeilschifter J, Wuster C, Vogel M, Enderes B, Ziegler R, Minne HW. Inflammation-mediated osteopenia (IMO) during acute inflammation in rats is due to a transient inhibition of bone formation. Calcif Tissue Int. 1987;41(6):321-325.

20. Von Wowern N, Stoltze K. Sex and age differences in bone morphology of mandibles. Scand J Dent Res. 1978;86(6):478-485.

21. Von Wowern N, Stoltze K. Age differences in cortical width of mandibles determined by histoquantitation. Scand J Dent Res. 1979;87(3):225-233.

22. Cao JJ, Wronski TJ, Iwaniec U, et al. Aging increases stromal/osteoblastic cell-induced osteoclastogenesis and alters the osteoclast precursor pool in the mouse. J Bone Miner Res. 2005;20(9):1659-1668.

23. Saglie FR, Simon K, Merrill J, Koeffler HP. Lipopolysaccharide from Actinobacillus actinomycetemcomitans stimulates macrophages to produce interleukin-1 and tumor necrosis factor mRNA and protein. Oral Microbiol Immunol. 1990;5(5):256-262.

24. Stashenko P, Fujiyoshi P, Obernesser MS, Prostak L, Haffajee AD, Socransky SS. Levels of interleukin 1 beta in tissue from sites of active periodontal disease. J Clin Periodontol. 1991;18(7):548-554.

25. Miyaura C, Inada M, Matsumoto C, et al. An essential role of cytosolic phospholipase A2alpha in prostaglandin E2-mediated bone resorption associated with inflammation. J Exp Med. 2003;197(10):1303-1310.

26. Miyauchi M, Hiraoka M, Oka H, et al. Immuno-localization of COX-1 and COX-2 in the rat molar periodontal tissue after topical application of lipopolysaccharide. Arch Oral Biol. 2004;49(9):739-746.

27. Ohishi M, Matsumura Y, Aki D, et al. Suppressors of cytokine signaling-1 and -3 regulate osteoclastogenesis in the presence of inflammatory cytokines. J Immunol. 2005;174(5):3024-3031.

28. Inada M, Matsumoto C, Uematsu S, Akira S, Miyaura C. Menbrane-bound prostaglandin E synthase-1-mediated prostaglandin E2 production by osteoblast plays a critical role in lipopolysaccharide-induced bone loss associated with inflammation. J Immunol. 2006;177(3):1879-1885.

29. Stashenko P, Goncalves RB, Lipkin B, Ficarelli A, Sasaki H, Campos-Neto A. Th1 immune response promotes severe bone resorption caused by Porphyromonas gingivalis. Am J Pathol. 2007;170(1): 203-213.

30. Shu L, Guan SM, Fu SM, Guo T, Cao M, Ding Y. Estrogen modulates cytokine expression in human periodontal ligament cells. J Dent Res. 2008;87(2):142-147. 